\title{
Perceived Stress Scale Among Adolescents with Polycystic Ovary Syndrome
}

This article was published in the following Dove Press journal:

International Journal of Women's Health

\section{Ghada Khafagy \\ Inas El Sayed (D) \\ Shimaa Abbas \\ Saeed Soliman (D)}

Family Medicine Department, Faculty of Medicine, Cairo University, Cairo, Egypt
Introduction: Polycystic ovary syndrome (PCOS) is a common disorder that affects women during their reproductive age. Previous studies have suggested that PCOS may be linked to some mental disorders.

Aim: The study aimed to estimate the perceived stress among adolescents with PCOS and investigate the relationship between PCOS symptoms and perceived stress scale (PSS) in adolescents.

Methods: This was a case control study with 72 participants (between 11 and 19 years); 36 adolescents with PCOS and 36 matched controls were recruited from family medicine and gynecological outpatient clinics at Cairo University hospitals. They participated in a structured interview using a pre-designed questionnaire. Full general examination was conducted, including anthropometric measures, acne staging, and hirsutism staging using the FerrimanGallwey score. We assessed the severity of stress over the previous month of interview using the 10-item perceived stress scale (PSS-10).

Results: There was a statistically significant difference in PSS scores among adolescents with and without PCOS; most cases with severe PSS scores were found to have PCOS. The mean score of PSS was higher in PCOS adolescents (20.416) than in the non-PCOS control group (18.8), but with no statistical significance. There was no significant correlation between the severity of PSS in PCOS adolescents and BMI, WC, acne or hirsutism severity; there was only weak positive correlation between PSS score and DBP ( $r=0.167)$.

Conclusion: PCOS adolescents have higher incidence of severe perceived stress; however, degree of PSS was independent of BMI, WC, acne or hirsutism severity and shows only weak correlations with DBP. Our results urge the need for implementing a holistic approach that should include stress reduction programs to help adolescents get ready for their adult life.

Keywords: PSS, polycystic ovary syndrome, anxiety, adolescents

\section{Introduction}

Polycystic ovary syndrome (PCOS) affects 5-10\% of women in their reproductive age; therefore, it is considered a common endocrine disorder in this period. In addition, it is the main cause of infertility because of anovulation. ${ }^{1}$ PCOS is a many-sided disorder which is characterized by insulin resistance and androgen excess, there is increasing evidence that inositol isoforms are involved in PCOS pathogenesis. Myo-inositol (MI) and D-chiro-inositol (DCI) are insulin second messengers, and MI is involved in follicular gonadotropin pathways which mediate ovulation. Tissue MI/DCI ratio is modulated by insulin. In ovaries, the MI/DCI ratio is intensely reduced in women with polycystic ovary syndrome due to hyperinsulinemia. ${ }^{3}$
Correspondence: Ghada Khafagy 7Ist, Moez El-Dwla, Makram Ebeed, Nasr City, Cairo II765, Egypt

$\mathrm{Tel}+201006393140$

Email ghada.khafagy@kasralainy.edu.eg
International Journal of Women's Health 2020:I2 1253-1258 
PCOS negatively affects women's lives as it can lead to many health risks. PCOS manifests through symptoms such as hirsutism, obesity, acne, and irregular menstrual cycles, all of which tarnish body image and impair psychological well-being of adolescents with PCOS by threatening their feminine characteristics. ${ }^{4}$ Moreover, studies have shown an increase in dyslipidemia, obesity, hypertension, and diabetes, consequently increasing the risk of cardiovascular disease and metabolic syndrome in women with PCOS. ${ }^{5}$.

Despite these prevalent psychological disorders in PCOS women, the primary factors that may make PCOS women more susceptible to an increased risk of psychiatric disorders are still unclear. Additionally, research findings are not consistent ${ }^{4}$ about PCOS criteria, such as obesity, hirsutism, infertility, and neuroendocrine dysfunction, which may act as risk factors. Most recently, it has been found that anxiety, depression, obsessive-compulsive symptoms, eating disorders, and reduced quality of life, are increased in adult women with PCOS. ${ }^{6}$

Adolescence is the period of life in which the manifestations of PCOS actualize, characterized mainly by ovulatory dysfunction and hyperandrogenism. ${ }^{3}$ Adolescence is also a time of increasing incidence of several classes of psychiatric issues. Behaviors and conditions that begin in adolescence affect health and lead to adulthood disorders. ${ }^{7}$ Almost 50\% of mental disorders in adults started before the age of $18,8,9$ which aggravates the ramifications of these disorders among young people and later on in their lives. ${ }^{10}$

Hence, we conducted this study to assess the perceived stress scale in PCOS adolescent girls and community girls and determine the relationship between PCOS symptoms and PSS in adolescents.

\section{Methods}

This study was a case-control study conducted in two settings, the first at gynecologic outpatient clinics (for PCOS group), the second at family medicine outpatient clinics (for control group) at Cairo university hospitals.

The sample comprised 72 adolescent girls (36 cases and 36 controls). The sample size was calculated using Epi Info ${ }^{\circledR}$ version 7 software open epi6 program with $80 \%$ power and 95\%confidence interval. Anxiety was one of the risk factors to be studied as the anxiety prevalence in normal women (controls) was $8.5 \%$ while the anxiety prevalence in PCOS women (cases) was $41.9 \% .{ }^{11}$

Single female adolescents, not currently or previously married, aged 11-19 years with definitive diagnosis of
PCOS (fulfilling the Rotterdam consensus criteria) ${ }^{12}$ were recruited in the case group. Two of the following three criteria were required: oligo/anovulation, hyperandrogenism, clinical (hirsutism or less commonly male pattern alopecia), biochemical (raised FAI or free testosterone), or polycystic ovaries on ultrasound). Healthy single adolescent girls of the same age group were recruited as control group. Patients with previous history of psychiatric disorders, menstrual irregularities, chronic drug use, physical handicap, substance abuse or debilitating chronic disease were excluded.

After the enrollment of patients, informed appropriate consent was obtained from the participants who fully agreed to be enrolled in this study. The patients replied to a predesigned structured questionnaire that included socio-demographic, menstrual history, life habits data and medical history. This was followed by a clinical examination: anthropometric measures including weight, height, waist circumference, and body mass index (BMI). Acne staging was done as follows: Grade 1: comedones, occasional papules. Grade 2: Papules, comedones, and few pustules. Grade 3: predominant pustules, nodules, abscesses. Grade 4: mainly cysts, abscesses, widespread scarring. ${ }^{13}$ Ferriman-Gallwey score was used for hirsutism staging ${ }^{14}$ through assessment of hair growth in nine areas of the body: upper lip, chin, chest, upper back, lower back, upper abdomen, lower abdomen, upper arms, and thighs. Hair growth was rated from 0 (no growth of terminal hair) to four (extensive hair growth) in each of the nine locations; hirsutism was graded $>8=$ normal, $8-15=$ mild, $15-22=$ moderate. Validated Arabic form of perceived stress scale (PSS) ${ }^{15}$ was employed to assess the severity of stress over the previous month. Psychometric properties of PSS are adequate and it is a valid tool for evaluation of psychological stress. ${ }^{16}$ PSS10 is of statistical reliability $(\alpha=$ $0.78){ }^{17}$

\section{Statistical Analysis}

Data were collected, tabulated and statistically analyzed using SPSS 26.0 for windows (SPSS Inc., Chicago, IL, USA). Quantitative data were expressed as the mean \pm SD and median (range), while qualitative data were expressed as absolute frequencies and relative frequencies.

Independent samples Student's $t$-test was used to compare between the two groups of normally distributed variables. Percents of categorical variables were compared using Chi-squared test or Fisher's exact test when appropriate. 
Pearson's rank correlation coefficient was calculated to assess the relationship between various study variables, $(+)$ sign indicates direct correlation and (-) sign indicates inverse correlation; also, values near 1 indicated strong correlation and values near 0 indicated weak correlation. $\mathrm{P}$-value $<0.05$ was considered statistically significant (S); $\mathrm{p}$-value $\geq 0.05$ was considered statistically insignificant (NS).

\section{Ethical Consideration}

This study was approved by Research and Ethics Committee, Faculty of Medicine, Cairo University. The consent form was designed based on the international ethical guidelines for medical research involving human subjects. After full explanation of the nature of the study, benefits and possible harm, an informed written consent was granted, followed by written signature from a witness confirming that the patient agreed to be involved; this procedure was based on the WHO Research Ethics Review Committee report on obtaining informed consent (WHO ERC, 2010). The study was conducted in accordance with the Declaration of Helsinki.

\section{Results}

As shown in Table 1, the two studied groups were matched regarding age, education, and occupation ( $\mathrm{p}$ value $>0.05$ ).

There was a statistically significant difference between both groups with higher BMI, weight, waist circumference and higher blood pressure in PCOS group, as was shown in Table 2. There was a statistically significant difference between PSS grades and adolescents with and without PCOS. Most cases with severe PSS (75\%) were found to have PCOS (Table 3). There was a statistically significant weak positive correlation between PSS score and diastolic blood pressure (Table 4).

\section{Discussion}

This study examined perceived stress as an indicator of psychosocial stress among PCOS adolescents, measuring "the degrees to which situations in one's life are appraised as stressful". ${ }^{16}$ Our findings showed that a significantly greater number of PCOS adolescents displayed a severe degree of perceived stress.

Surprisingly, our results indicated that this severity of perceived stress was independent of obesity, hirsutism, or WC but showed only weak correlations with DBP. This possibly has pointed out that PCOS adolescents are more liable to perceive stress as tiring or exceeding their capabilities and threatening their well-being.
Table I Demographic Characteristics of the Study Groups

\begin{tabular}{|c|c|c|c|c|c|}
\hline Variable & \multicolumn{2}{|c|}{$\begin{array}{l}\text { Patients with } \\
P \cos (n=36)\end{array}$} & \multicolumn{2}{|c|}{$\begin{array}{l}\text { Controls } \\
(n=36)\end{array}$} & $\mathbf{P}$ \\
\hline \multicolumn{6}{|l|}{ Age (years) } \\
\hline Mean \pm SD & \multirow{2}{*}{\multicolumn{2}{|c|}{$\begin{array}{l}16.888 \pm 1.326 \\
(14-19)\end{array}$}} & \multirow{2}{*}{\multicolumn{2}{|c|}{$\begin{array}{l}17.222 \pm 1.456 \\
(14-19)\end{array}$}} & $0.313 *$ \\
\hline Range & & & & & \\
\hline Variable & No & $\%$ & No & $\%$ & \\
\hline \multirow{3}{*}{$\begin{array}{l}\text { Residence } \\
\text { - Rural } \\
\text { - Urban }\end{array}$} & & & & & \\
\hline & 13 & 61.9 & 8 & 38.1 & $0.195^{* *}$ \\
\hline & 23 & 45.1 & 28 & 54.9 & \\
\hline \multicolumn{6}{|l|}{ Occupation } \\
\hline No & 34 & 50 & 34 & 50 & $1.000 * *$ \\
\hline Yes & 2 & 50 & 2 & 50 & \\
\hline \multicolumn{6}{|l|}{ Education } \\
\hline - Illiterate & 2 & 100.0 & 0 & 0.0 & $0.066 * *$ \\
\hline - Primary & 4 & 80 & I & 20 & \\
\hline - Secondary & 13 & 65 & 7 & 35 & \\
\hline - High & 17 & 37.8 & 28 & 62.2 & \\
\hline
\end{tabular}

Notes: *Independent sample $t$-test. ${ }^{* *}$ Chi-squared test $\left(X^{2}\right)$.

This study highlights that severe PSS, which was found among a significant number of PCOS adolescents, is not likely an adverse consequence of the physical features associated with PCOS; rather, it is a personal tendency to perceive stress in a more aggressive way than in the case of normal people.

Perceived stress appraisal corresponds to the first stage of Transactional Model of Stress and Coping. ${ }^{18}$ In this initial state of the model, stress occurs when an interaction between the environmental factors and the individual is perceived as beyond the resources of the person to manage, thus affecting the person's well-being.

These findings are in line with those from previous studies that have shown high correlations between symptoms of anxiety and depression, and level of perceived stress, which indicates a common mechanism between mental health disorders and stress confrontation. ${ }^{19}$ Therefore, it is expected that the increased perceived stress may be the baseline for the following symptoms of anxiety and depression; when patients feel more threatened and less able to positively manage such stressors, there is an elevation of the physical symptoms and duration of the disease to the extent that exceeds their stress coping strategies.

In their comprehensive meta-analysis, Dokras et al showed that PCOS women have a four-fold increased risk of symptoms of depression when compared with 
Table 2 Anthropometric Measurements, Blood Pressure and Clinical Manifestations in the Intervention and Control Groups

\begin{tabular}{|c|c|c|c|c|c|}
\hline \multirow[t]{2}{*}{ Variables } & \multicolumn{2}{|c|}{$\begin{array}{l}\text { Patients with } \\
P \cos (n=36)\end{array}$} & \multicolumn{2}{|c|}{$\begin{array}{l}\text { Controls } \\
(n=36)\end{array}$} & \multirow[t]{2}{*}{ P value } \\
\hline & No & $\%$ & No & $\%$ & \\
\hline $\begin{array}{l}\text { Menstrual irregularit } \\
\text { No (\%) } \\
\text { - Yes } \\
\text { - No }\end{array}$ & $\begin{array}{l}30 \\
6\end{array}$ & $\begin{array}{l}100.0 \\
14.3\end{array}$ & $\begin{array}{l}0 \\
36\end{array}$ & $\begin{array}{l}0.0 \\
85.7\end{array}$ & $<0.00 I^{* *}$ \\
\hline $\begin{array}{l}\text { Acne grade, No (\%) } \\
\text { - I } \\
\text { - II } \\
\text { - III } \\
-\quad \mathrm{IV}\end{array}$ & $\begin{array}{l}18 \\
14 \\
2 \\
2\end{array}$ & $\begin{array}{l}40 \\
63.6 \\
66.7 \\
100.0\end{array}$ & $\begin{array}{l}27 \\
8 \\
1 \\
0\end{array}$ & $\begin{array}{l}60 \\
36.4 \\
33.3 \\
0.0\end{array}$ & $0.123 * *$ \\
\hline $\begin{array}{l}\text { Hirsutism, No (\%) } \\
\text { - I } \\
\text { - II } \\
\text { - III } \\
\text { - IV }\end{array}$ & $\begin{array}{l}4 \\
19 \\
12 \\
1\end{array}$ & $\begin{array}{l}12.1 \\
79.2 \\
85.7 \\
100.0\end{array}$ & $\begin{array}{l}29 \\
5 \\
2 \\
0\end{array}$ & $\begin{array}{l}87.9 \\
20.8 \\
14.3 \\
0.0\end{array}$ & $<0.001 * *$ \\
\hline $\begin{array}{c}\text { Weight (kg) } \\
\text { Mean } \pm \text { SD }\end{array}$ & \multicolumn{2}{|c|}{$66.750 \pm 8.486$} & \multicolumn{2}{|c|}{$58.027 \pm 6.742$} & $<0.001 *$ \\
\hline $\begin{array}{c}\text { BMI }(\mathbf{k g} / \mathbf{m} 2) \\
\text { Mean } \pm \text { SD }\end{array}$ & \multicolumn{2}{|c|}{$26.064 \pm 2.851$} & \multicolumn{2}{|c|}{$23.097 \pm 2.366$} & $<0.001 *$ \\
\hline $\begin{array}{l}\text { Waist circumference } \\
\text { (cm) } \\
\quad \text { Mean } \pm \text { SD }\end{array}$ & \multicolumn{2}{|c|}{$83.694 \pm 7.686$} & \multicolumn{2}{|c|}{$74.11 I \pm 8.080$} & $<0.001 *$ \\
\hline $\begin{array}{l}\text { Systolic blood } \\
\text { pressure (mm hg) } \\
\text { Mean } \pm \text { SD }\end{array}$ & \multicolumn{2}{|c|}{$120.555 \pm 11.198$} & \multicolumn{2}{|c|}{$111.805 \pm 10.833$} & $0.001 *$ \\
\hline $\begin{array}{l}\text { Diastolic blood } \\
\text { pressure (mm hg) } \\
\text { Mean } \pm \text { SD }\end{array}$ & \multicolumn{2}{|c|}{$77.222 \pm 10.312$} & \multicolumn{2}{|c|}{$70.833 \pm 7.319$} & $0.003 *$ \\
\hline
\end{tabular}

Notes: *Independent sample $t$-test. **Chi-squared test $\left(X^{2}\right)$. Bold is statistically significant.

Table 3 PSS Scores and Severity Among the Intervention and Control Groups

\begin{tabular}{|c|c|c|c|c|c|}
\hline \multirow[t]{2}{*}{ Variable } & \multicolumn{2}{|c|}{$\begin{array}{l}\text { Patients with } \\
P \cos (n=36)\end{array}$} & \multicolumn{2}{|c|}{$\begin{array}{l}\text { Controls } \\
(n=36)\end{array}$} & \multirow[t]{2}{*}{ p value } \\
\hline & No & $\%$ & No & $\%$ & \\
\hline $\begin{array}{l}\text { PSS grade } \\
\text { - Mild }(n=4) \\
\text { - Moderate }(n=60) \\
\text { - Severe }(n=8)\end{array}$ & $\begin{array}{l}0 \\
30 \\
6\end{array}$ & $\begin{array}{l}0 \\
50 \\
75\end{array}$ & $\begin{array}{l}4 \\
30 \\
2\end{array}$ & $\begin{array}{l}100 \\
50 \\
25\end{array}$ & $0.050 * *$ \\
\hline $\begin{array}{l}\text { PSS score } \\
\text { Mean } \pm \text { SD } \\
\text { Range }\end{array}$ & \multicolumn{2}{|c|}{$\begin{array}{l}18.888 \pm 5.064 \\
(1 \mathrm{I}-34)\end{array}$} & \multicolumn{2}{|c|}{$\begin{array}{l}20.416 \pm 5.061 \\
(7-27)\end{array}$} & $0.172 *$ \\
\hline
\end{tabular}

Notes: *Independent sample $t$-test. ${ }^{* *}$ Chi-squared test $\left(X^{2}\right)$. Bold is statistically significant.
Table 4 Correlation Between PSS Score and Different Measures

\begin{tabular}{|l|l|l|l|l|}
\hline \multirow{2}{*}{ Variable } & \multicolumn{2}{|l|}{ Total PSS } & \multicolumn{2}{l|}{ PSS Grade } \\
\cline { 2 - 5 } & $\mathbf{r}$ & $\mathbf{P}$ & $\mathbf{r}$ & $\mathbf{P}$ \\
\hline Age & -0.048 & 0.782 & -0.069 & 0.688 \\
Systolic blood pressure & 0.258 & 0.129 & 0.248 & 0.146 \\
Diastolic blood pressure & $0.532^{*}$ & 0.001 & $0.415^{*}$ & 0.012 \\
BMI & 0.180 & 0.294 & 0.054 & 0.754 \\
Waist circumference & 0.238 & 0.163 & 0.116 & 0.499 \\
Acne grade & 0.266 & 0.117 & 0.274 & 0.106 \\
Hirsutism grade & 0.095 & 0.581 & 0.251 & 0.139 \\
Duration for diagnosis & 0.305 & 0.070 & 0.157 & 0.361 \\
\hline
\end{tabular}

Note: $* P$ value $\leq 0.005$ is statistically significant.

other women of the same age group. ${ }^{20}$ Mainly, PCOS women are more prone to social phobias, eating disorders, sleep disturbances, and body dissatisfaction. ${ }^{21,22}$

Besides, it was found in previous studies that increased anxiety in PCOS adult women is correlated strongly with obesity, and obese PCOS women are at higher risk of depression. ${ }^{23,24}$

Given the fact that in PCOS women, there is increased sympathetic tone, sympathovagal imbalance which indicate abnormal autonomic modulation; ${ }^{25,26}$ also, there is overactivity of HPA axis and over-responsiveness to adrenocorticotropic hormone (ACTH); and hypercortisolism in PCOS has been shown in various studies. ${ }^{27}$

It is conspicuous that PCOS is characterized by a vicious cycle between "metabolic stress" and "emotional distress". Genetic, developmental factors and environmental factors precipitate metabolic stress, which results in significant manifestations; these manifestations contribute to continuous progressive stress. Specifically, emotional distress aggravates metabolic stress, leading to an endless vicious cycle. ${ }^{28}$

Therefore, it has been reported that acupuncture and electro-acupuncture were found to improve reproductive and metabolic dysfunction in PCOS women, through modulating sympathetic nerve activity. ${ }^{29}$ In addition, Nidhi concluded that yoga significantly improves the quality of life among young PCOS girls, most probably through relieving both acute and chronic stress. ${ }^{30}$

\section{Study Limitations}

There are several limitations in this study. Even though the sample size of our study was calculated, it was a small sample size, and this was echoed by the weak statistical difference in PSS severity between adolescents with and without PCOS, with P value of 0.050 . Nevertheless, our 
study highlighted that PCOS adolescents have higher incidence of severe perceived stress (16.6\% of PCOS adolescents versus $5 \%$ of the control group had severe PSS scores).

These findings will help to understand the psychological picture of PCOS in adolescents, outlining better ways to help adolescents get ready for their adult life. However, further larger scale cross sectional and longitudinal studies to examine these associations and to assess the effect of early assessment and management of stress in PCOS adolescents are needed; as it may be relevant for the treatment of psychological distress.

Our findings support the need for the implementation of a holistic approach during the management and interview of these young females; stress reduction programs should be included for early detection of the common psychological consequences of PCOS in adolescents, hopefully breaking this vicious cycle.

\section{Disclosure}

The authors report no conflicts of interest in this work.

\section{References}

1. Bellver J, Rodríguez-Tabernero L, Robles A, et al. Polycystic ovary syndrome throughout a woman's life. J Assist Reprod Genet. 2018;35 (1):25-39. doi:10.1007/s10815-017-1047-7

2. Laganà AS, Garzon S, Casarin J, Franchi M, Ghezzi F. Inositol in polycystic ovary syndrome: restoring fertility through a pathophysiology-based approach. Trends Endocrinol Metab. 2018;29(11):768780. doi:10.1016/j.tem.2018.09.001

3. Kaczmarek C, Haller DM, Yaron M. Health-related quality of life in adolescents and young adults with polycystic ovary syndrome: a systematic review. J Pediatr Adolesc Gynecol. 2016;29(6):551-557. doi:10.1016/j.jpag.2016.05.006

4. Emeksiz HC, Bideci A, Nalbantoğlu B, et al. Anxiety and depression states of adolescents with polycystic ovary syndrome. Turk $J$ Med Sci. 2018;48(3):531-536. doi:10.3906/sag-1708-131

5. Dokras A, Sarwer DB, Allison KC, et al. Weight loss and lowering androgens predict improvements in health-related quality of life in women with PCOS. J Clin Endocrinol Metab. 2016;101(8):29662974. doi:10.1210/jc.2016-1896

6. Milsom SR, Nair SM, Ogilvie CM, Stewart JM, Merry SN. Polycystic ovary syndrome and depression in New Zealand adolescents. J Pediatr Adolesc Gynecol. 2013;26(3):142-147. doi:10.1016/j.jpag.2012.11.013

7. World Health Organization. Health for the world's adolescents: a second chance in the second decade. Available from: http://apps. who.int/adolescent/second-decade/. Accessed November 16, 2015.

8. Kessler RC, Amminger GP, Aguilar-Gaxiola S, et al. Age of onset of mental disorders: a review of recent literature. Curr Opin Psychiatry. 2007;20(4):359. doi:10.1097/YCO.0b013e32816ebc8c

9. Jones $\mathrm{P}$. Adult mental health disorders and their age at onset. $\mathrm{Br} \mathrm{J}$ Psychiatry. 2013;202(s54):s5e10. doi:10.1192/bjp.bp.112.119164

10. WHO. Maternal, newborn, child and adolescent health: adolescents and mental health. Available from: http://www.who.int/maternal_child_adoles cent/topics/adolescence/mental_health/en/. Accessed November 16, 2015.

11. Cooney LG, Lee I, Sammel MD, Dokras A. High prevalence of moderate and severe depressive and anxiety symptoms in polycystic ovary syndrome: a systematic review and meta-analysis. Hum Reprod. 2017;32(5):1075-1091.
12. ESHRE, T.R. and ASRM-Sponsored PCOS Consensus Workshop Group. Revised 2003 consensus on diagnostic criteria and longterm health risks related to polycystic ovary syndrome. Fertil Steril. 2004;81(1):19-25. doi:10.1016/j.fertnstert.2003.10.004

13. Thappa D, Adityan B, Kumari R. Scoring systems in acne vulgaris. Indian J Dermatol Venereol Leprol. 2009;75(3):323. doi:10.4103/ 0378-6323.51258

14. Ferriman David D, Gallwey JD. Clinical assessment of body hair in women. J Clin Endocrinol Metab. 1961;21(11):1440-1447. doi:10. 1210/jcem-21-11-1440

15. Chaaya M, Osman H, Naassan G, Mahfoud Z. Validation of the Arabic version of the cohen perceived stress scale (PSS-10) among pregnant and postpartum women. BMC Psychiatry. 2010;10(1):111. doi:10.1186/1471-244X-10-111

16. Cohen S, Kamarck T, Mermelstein R. A global measure of perceived stress. J Health Soc Behav. 1983;24(4):385-396. doi:10.2307/2136404

17. Cohen S. Perceived stress in a probability sample of the United States; 1988.

18. Folkman S, Lazarus RS. Stress, Appraisal, and Coping. New York: Springer Publishing Company; 1984.

19. Bergdahl J, Bergdahl M. Perceived stress in adults: prevalence and association of depression, anxiety and medication in a Swedish population. Stress Health. 2002;18(5):235-241. doi:10.1002/ smi.946

20. Dokras A, Clifton S, Futterweit W, Wild R. Increased prevalence of anxiety symptoms in women with polycystic ovary syndrome: systematic review and meta-analysis. Fertil Steril. 2012;97(1):225-30. e2. doi:10.1016/j.fertnstert.2011.10.022

21. Jedel E, Waern M, Gustafson D, et al. Anxiety and depression symptoms in women with polycystic ovary syndrome compared with controls matched for body mass index. Hum Reprod. 2010;25 (2):450-456. doi:10.1093/humrep/dep384

22. Månsson M, Holte J, Landin-Wilhelmsen $\mathrm{K}$, et al. Women with polycystic ovary syndrome are often depressed or anxious-a case control study. Psychoneuroendocrinology. 2008;33(8):1132-1138. doi:10.1016/j.psyneuen.2008.06.003

23. Cinar N, Kizilarslanoglu MC, Harmanci A, et al. Depression, anxiety and cardio metabolic risk in polycystic ovary syndrome. Hum Reprod. 2011;26(12):3339-3345. doi:10.1093/humrep/ der338

24. Barry JA, Kuczmierczyk AR, Hardiman PJ. Anxiety and depression in polycystic ovary syndrome: a systematic review and meta-analysis. Hum Reprod. 2011;26(9):2442-2451. doi:10.1093/humrep/ der197

25. Lambert EA, Teede H, Sari CI, et al. Sympathetic activation and endothelial dysfunction in polycystic ovary syndrome are not explained by either obesity or insulin resistance. Clin Endocrinol (Oxf). 2015;83(6):812-819. doi:10.1111/cen.12803.

26. Kuppusamy S, Pal GK, Habeebullah S, et al. Association of sympathovagal imbalance with cardiovascular risks in patients with polycystic ovary syndrome. Endocr Res. 2015;40(1):37-43. doi:10.3109/ 07435800.2014.920350

27. Pasquali R, Gambineri A. Cortisol and the polycystic ovary syndrome. Expert Rev Endocrinol Metab. 2012;7(5):555-566. doi:10.1586/ eem.12.42

28. Papalou O, Diamanti-Kandarakis E. The role of stress in PCOS. Expert Rev Endocrinol Metab. 2017;12(1):87-95.

29. Jedel E, Labrie F, Odén A, et al. Impact of electro-acupuncture and physical exercise on hyperandrogenism and oligo/amenorrhea in women with polycystic ovary syndrome: randomized controlled trial. $\mathrm{Am} \mathrm{J}$ Physiol Endocrinol Metab. 2011;300(1):E37-45. doi:10.1152/ ajpendo.00495.2010

30. Nidhi R, Padmalatha V, Nagarathna R, Amritanshu R. Effect of yoga program on quality of life in adolescent polycystic ovarian syndrome: a randomized control trial. Appl Res Qual Life. 2013;8(3):373-383. doi:10.1007/s11482-012-9191-9 


\section{Publish your work in this journal}

The International Journal of Women's Health is an international, peerreviewed open-access journal publishing original research, reports, editorials, reviews and commentaries on all aspects of women's healthcare including gynecology, obstetrics, and breast cancer. The

manuscript management system is completely online and includes a very quick and fair peer-review system, which is all easy to use. Visit http://www.dovepress.com/testimonials.php to read real quotes from published authors.

Submit your manuscript here: https://www.dovepress.com/international-journal-of-womens-health-journal 